\title{
¿Horario Valle o Punta? Movilidad cotidiana e imaginarios urbanos en Talca'
}

\author{
Tomás Errázuriz² y Eduardo Valdés ${ }^{3}$
}

\begin{abstract}
RESUMEN
Considerando las profundas transformaciones que han afectado a la movilidad cotidiana en Talca durante la última década, el presente estudio reflexiona sobre la forma en que los individuos experimentan dichos cambios, a partir de sus prácticas cotidianas de viaje y como estas percepciones validan, significan y configuran ciertas maneras de entender e imaginar la ciudad. En base a 25 entrevistas a personas que viajan cotidianamente por Talca, este estudio reconoce dos imaginarios urbanos coexistentes que han sido denominados: ciudad "horario valle" y ciudad "horario punta". Mientras el primero se asocia a la tranquilidad y previsibilidad de una ciudad acotada, el segundo da cuenta de las tensiones, incertidumbres y ansiedades asociadas tradicionalmente al espacio metropolitano, que por momentos invade las calles de Talca. Finalmente, se reflexiona sobre los quiebres que suponen las conquistas del "horario punta", y la progresiva diferenciación de las experiencias de movilidad dependiendo de las posibilidades de acceso a ciertos bienes y espacios urbanos.
\end{abstract}

Palabras clave: Talca, movilidad cotidiana, imaginarios urbanos.

\begin{abstract}
Considering the profound changes that have affected the daily mobility in Talca during the last decade, this study looks at how individuals experience such changes from their daily travel practices and how these perceptions validate, signify and configure certain ways of understanding and imagining the city. Based on 25 interviews with people who travel on a daily basis through Talca, this study recognizes two coexisting urban imaginaries that have been identified as the "peak" and the "off-peak" city. While the former is associated with tranquility and predictability of a bounded city, the second results in tensions, uncertainties and anxieties, which have been traditionally associated with metropolitan space. Finally, we reflect on the paradoxes gained by the achievements of the "peak city" and the progressive differentiation of mobility experiences depending on the possibilities of access to certain goods and urban spaces.
\end{abstract}

Key words: Talca, daily mobility, urban imaginaries.

Este trabajo fue posible gracias al apoyo de Conicyt a través del proyecto Fondecyt Regular 1130695. Artículo recibido el 18 de enero de 2016, aceptado el 7 de abril de 2017 y corregido el 28 de julio de 2017.

Académico en Campus Creativo, Universidad Andrés Bello (Chile).E-mail: tomaserrazuriz@gmail.com

Antropólogo, Universidad de Chile (Chile). 
Desde fines de la década de 1980, la geografía del transporte ha desarrollado una línea de trabajos que exploran las relaciones entre transporte y procesos sociales, centrándose la mayor parte en un nivel estructuralista (Widmer y Schneider 2006 citado en Salerno, 2012). Estos trabajos generalmente estudian en una escala macro, reconociendo variables, tendencias y patrones que tienden a confirmar la relevancia del transporte en el ámbito económico, político, metropolitano, etc. Una vertiente posterior hace foco en la accesibilidad o en el transporte como posibilidad, aunque en general tiende a concentrarse en la oferta de transporte y no en los individuos (Salerno 2006). Sólo durante los últimos años se generado un vuelco hacia enfoques que tienen por centro al individuo (Cebollada y Avellaneda, 2008; Miralles-Guasch, 2002).

Otras disciplinas vinculadas a las ciencias sociales -entre las que destacan la planificación urbana, la economía, la geografía, la psicología, etc. -, han seguido trayectorias similares en sus aproximaciones al tema de transporte urbano, pasando de las variables estructurales a otras más inclinadas a lo etnográfico y cualitativo (Schifelbusch, 2009). Esta tendencia es reforzada hacia fines de los años 90 con lo que se ha denominado el Mobility turn o el nuevo paradigma de la movilidad. Creswell (2006) entendiendo la movilidad como fenómeno inherente a lo humano -que comprende desde las patadas del bebé antes de nacer hasta los viajes internacionales de negocio-, se refiere a esta como una faceta geográfica fundamental de la existencia, con capacidad de proveer un terreno fértil desde donde pueden construirse y se han construido narrativas e ideologías múltiples.

Específicamente para los estudios del transporte, el giro de la movilidad implica trascender lo material y sistémico, para atender a la experiencia misma del desplazamiento, las interacciones sociales, las percepciones, ideas, sentimientos, valores y recuerdos que los sujetos asocian a esta experiencia. Mientras el movimiento es el equivalente dinámico de un espacio y tiempo abstracto, aparentemente natural y desprovisto de significados; la movilidad viene siendo el equivalente dinámico de un tiempo social y de un lugar, entendido como espacio imbuido de sentido y poder (Creswell, 2006).

En esta misma línea, Sheller y Urry (2006), postulan que históricamente las ciencias sociales concibieron el fenómeno del viaje cotidiano como una caja negra: un conjunto neutral de tecnologías y procesos que favorecen formas de vida económica, social y política que resultan explicables sólo en función de otros procesos que se fundan en la causalidad. En respuesta, estos autores establecen que es fundamental superar la mirada estática con que las ciencias sociales se han aproximado a este problema, bajo la idea de que los procesos sociales están insertos en una compleja red de flujos y movimientos constantes. Así, la experiencia cotidiana del viaje, que tradicionalmente había sido estudiada como mecanismo para identificar variables que condicionan las decisiones de cómo llegar a un destino (niveles de comodidad, seguridad, tranquilidad), deja de ser observada instrumentalmente, y se vuelve un objeto de estudio en sí misma. Desde esta perspectiva, el acto de viajar, no consiste meramente en trasladarse de un punto $A$ a otro $B$, sino que constituye un espacio social que se configura en base al ensamblaje siempre variable de personas, objetos, lugares, imágenes e ideas.

Se quiebra así la tendencia seguida por los estudios del transporte que ha tendido a diferenciar entre los viajes y las actividades y surge la posibilidad de pensar los viajes como espacios de habitabilidad donde múltiples actividades tienen lugar. También se cuestiona la distinción tradicional entre lugares y personas, en donde los primeros se entienden como espacios estables 
que funcionan como atractores o expulsores de los segundos. En cambio, se propone que lugares y personas establecen relaciones dinámicas que los mantienen en permanente transformación, influyéndose mutuamente (Hannam et al., 2006). Esta aproximación, en cierta medida, retoma y profundiza la consigna que varias décadas atrás formulaba Hägerstrand, cuando establecía la "geografía del tiempo", como enfoque que se interesa por el modo en que los individuos hacen uso del tiempo y del espacio para conseguir sus fines (Mendizabal, 2013).

En Chile, aún de manera incipiente, diversos investigadores se han enfocado en los espacios de desplazamientos superando la aproximación tradicional de los estudios del transporte. La mayoría de estos trabajos han sido desarrollados en torno a problemáticas actuales asociadas a la movilidad cotidiana de la ciudad de Santiago. Entre estos, destacan estudios que miran la implementación del Transantiago y las prácticas que desarrollan los individuos frente a las desigualdades del transporte público (Ureta, 2008; Jouffe y Lazo, 2010; Jirón, 2010, 2013); buscan comprender la movilidad también como una forma de exclusión y segregación socio-espacial (Jirón, 2007; Lazo, 2008); o aproximaciones que analizan nuevos actores y usos asociados al aumento de automóviles particulares (Errazuriz, 2009; Ureta, 2009).

Históricamente, la ciudad de Santiago ha concentrado la atención de las autoridades y especialistas en temas de transporte y movilidad. Este desequilibrio se puede observar en la producción de estudios y conocimiento crítico sobre los fenómenos de la movilidad en otras regiones. Resulta preocupante, en este sentido, buscar literatura académica sobre las transformaciones del transporte y la movilidad durante las últimas décadas que no tengan por caso de estudio la ciudad de Santiago, y descubrir que la producción es mínima y para la mayoría de las ciudades y territorios chilenos, inexistente. Cómo en muchos otros ámbitos del conocimiento, la centralización del capital humano en la Región Metropolitana ha favorecido el desarrollo de temáticas y enfoques que surgen desde las preocupaciones e intereses del contexto metropolitano. Esta falta de atención contrasta con la intensidad que muestran los cambios en el transporte y la movilidad en regiones, en muchas ocasiones incluso mayores que en la capital.

En contra de la tendencia, este estudio busca centrar su mirada en un tipo de ciudad que si bien posee una posición geopolítica estratégica en los territorios en los que se ubica, se aleja del modelo de expansión metropolitano. Este tipo de urbe, a diferencia de la gran capital, han sido las que más han aumentado su población durante los últimos 30 años, a partir de un modelo basado en la extracción y exportación de materias primas provenientes de actividades agropecuarias, pesqueras y forestales (Canales y Canales, 2013). Ciudades del Valle central como Curicó, Rancagua, Chillán y Talca poseen dinámicas socio-territoriales diferentes de los centros metropolitanos como Santiago, Valparaíso y Concepción. La mutua dependencia entre los sectores rurales agrícolas, pecuarios y forestales con los servicios que ofrecen las zonas urbanas, constituyen la Agrópolis (Canales y Canales, 2013), en donde la relación centro-periferia se vuelve aún más profunda, en términos sociales y productivos, a diferencia del desanclaje que se observa en las metrópolis del mundo sobremoderno (Castells, 1999).

Cuando se observan las cifras de crecimiento del parque automotriz más allá de la capital, es evidente la intensidad que muestran los cambios en los últimos cinco años. Mientras la Región Metropolitana (RM) incrementó los vehículos motorizados entre el 2009 y 2014 en 39,9\%, las restantes regiones del país lo hicieron en un $49,8 \%$. La diferencia es mayor cuando se observa el caso de la provincia de Talca, y específicamente las dos comunas hacia las cuales ha crecido la ciudad 
en la última década: Maule y San Clemente. Éstas comunas, que muestran los mayores índices a nivel nacional, han crecido 113,3 "\% y $87,7 \%$ respectivamente (INE, 2009; INE, 2014).

A las variaciones en el parque vehicular, se agregan importantes deficiencias en infraestructura vial (pavimentación, ensanches, señalética, etc.) en consideración de las necesidades. No es extraño, en este sentido, la aparición de otras problemáticas históricamente asociadas a los grandes centros urbanos, pero que hoy afectan sin distinción a ciudades de tamaño intermedio, tales como la contaminación ambiental o la congestión vehicular.

Aunque entre círculos de expertos no es novedad la intensificación de las transformaciones urbanas de algunas capitales regionales por sobre la RM, permanece sin atención alguna las consecuencias que estos cambios tiene sobre las experiencias y percepciones del viaje entre los habitantes de estas localidades. Buscando aportar a esta discusión, el presente estudio tiene por objeto describir y analizar cómo estas transformaciones urbanas han afectado la experiencia de viaje de quienes diariamente se trasladan dentro de la ciudad de Talca y en sus alrededores y cómo esta nueva ciudad vivida actúa además sobre los imaginarios de los lugares que se habitan.

Entendiendo que la metodología para estudiar el ámbito de los imaginarios supone evitar la fragmentación de lo estudiado en variables aisladas, y teniendo como referente la propuesta de los hologramas espaciales (Lindón, 2007), se busca interrogar a distintas personas sobre aquellos lugares y prácticas concretas que caracterizan sus trayectos cotidianos, entendiendo que el relato de "prácticas, lugares, escenarios" contendrá "otros lugares, sentido de los lugares, intencionalidades de los habitantes de esos lugares, simbolizaciones de los lugares y del quehacer que en ellos se concreta" (Lindón, 2007:43).

En base al análisis de las 25 entrevistas que se realizaron a personas que viajan regularmente por la ciudad y la confección de cartografías en donde se registran sus trayectos actuales, históricos y diversos espacios significativos, se ha reconocido en la mayoría de los relatos una coexistencia entre dos imaginarios de ciudad, habitualmente representados en constante tensión. El primero, que hemos denominado "Ciudad horario valle", alude al recuerdo de aquella ciudad previa, y se asocia a sensaciones de tranquilidad, cercanía, certezas; mientras que el segundo, denominado "Ciudad horario punta", es el producto de las transformaciones modernizadoras que se han intensificado en el territorio durante los últimos años. Aunque ambas ideas de ciudad se encuentran temporal y espacialmente delimitadas, existe la percepción de que, durante los últimos años, la segunda ha avanzado en detrimento de la primera, extendiendo su radio de influencia e intensidad. Se sostiene, por último, que este avance sería diferenciado según las posibilidades distintas de acceso a ciertos bienes y espacios urbanos.

\section{Una ciudad en transformación}

Para comprender las transformaciones que ha experimentado la movilidad, específicamente en Talca, es necesario delimitar el contexto socio-territorial que ha marcado a esta ciudad en los últimos años. Talca es la capital de la Región del Maule, razón por la cual sirve como centro político-administrativo para muchas ciudades aledañas y poblados rurales. Durante los últimos años ha presentado un aumento poblacional no despreciable alcanzando los 250.025 habitantes (CASEN, 2013), los que se enmarcan dentro de un proceso generalizado de crecimiento, relativo 
a ciudades de tamaño medio, vinculado al desarrollo de la industria extractivista y de exportación agrícola, minera y forestal (Canales y Canales, 2012). En este contexto, los flujos de población que habitan en sectores rurales y ciudades de menor tamaño, requieren de la mayor oferta de servicios existentes en las capitales, especialmente puestos de trabajo e instituciones educativas. Ejemplo de ello es la consolidación de la ciudad de Talca como una ciudad con una amplia oferta de educación superior, lo cual atrae a jóvenes estudiantes, no solo de las distintas localidades y ciudades del Maule, sino que también de otras regiones (INE, 2014). Por otra parte, otro elemento que ha influido en el aumento poblacional de la ciudad, ha sido la mayor oferta habitacional concentrada en los lindes de ésta, específicamente en el sector oriente, norte y sur-poniente, donde se ha generado una incipiente conurbación con la vecina comuna de Maule. Estos dos últimos sectores, corresponden a viviendas sociales y de familias provenientes de Santiago. Por su parte, el sector oriente presenta una oferta habitacional correspondiente a loteos, parcelas de agrado y viviendas de mayor valor (MINVU, 2007; ELCl, 2010). Pese a esta expansión urbana concentrada en las periferias, las dinámicas territoriales siguen siendo fuertemente dependientes del centro de la ciudad, en donde se concentra la mayor parte del comercio y los servicios.

Con el terremoto del 2010 gran parte del casco antiguo del centro de la ciudad se vio severamente afectado, lo cual produjo que parte considerable del grupo residencial, ante la insuficiencia de subsidios de reconstrucción, se vieran forzados a dejar sus casas y ser trasladados a nuevos barrios, ubicados en sectores periféricos, (Letelier y Boyco, 2011) tal como se expone en la Figura $N^{\circ}$ 1. Finalmente, y a un año del cataclismo, se actualiza el Plan Regulador Comunal, donde

Figura $\mathrm{N}^{\circ} 1$

Localización original y relocalizaciones en nuevos conjuntos post-terremoto

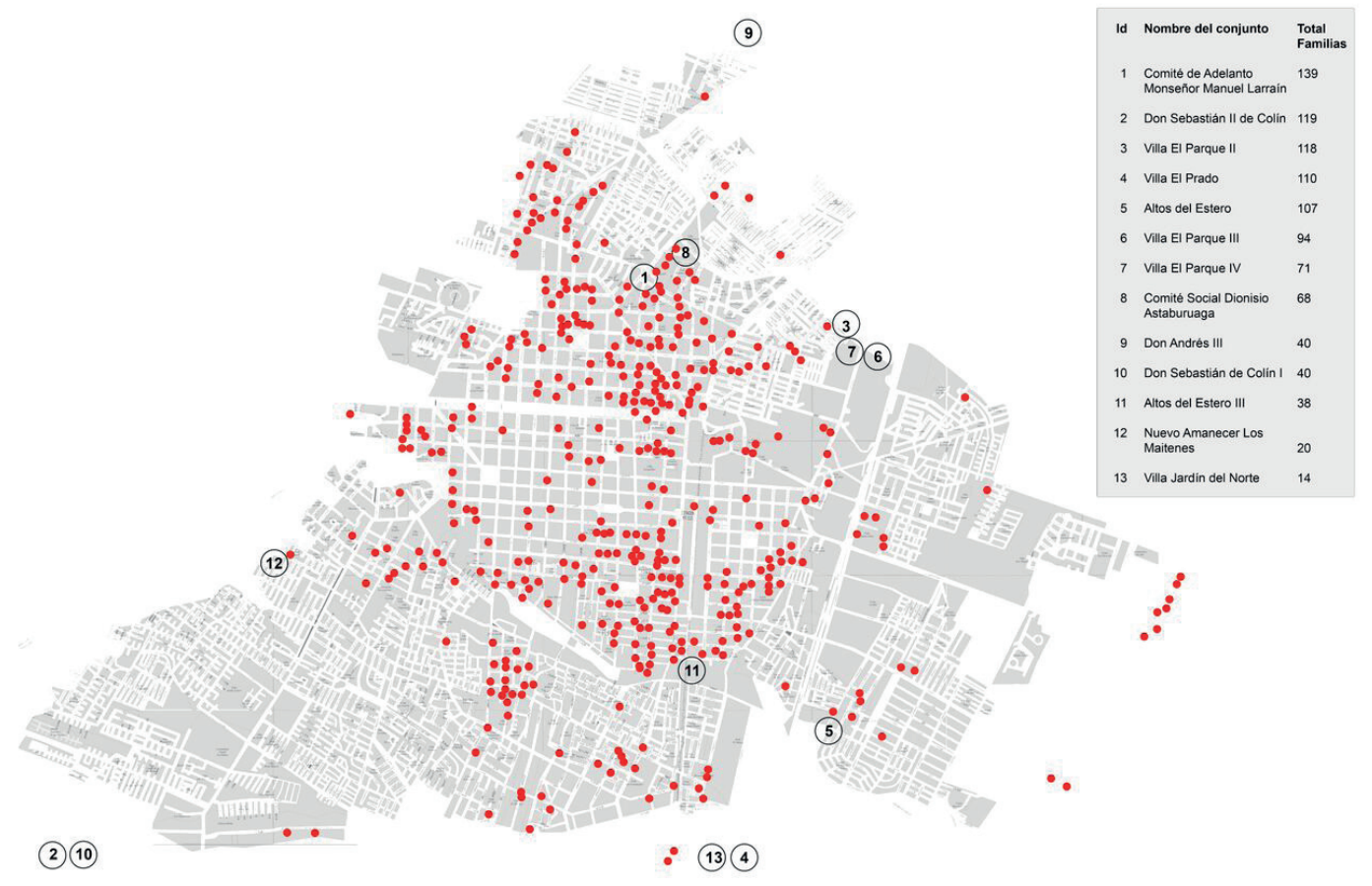

Fuente: CEUT, 2011 
se puede observar un notable aumento de la superficie urbana, pasando de 3.508 a $10.467 \mathrm{Ha}$., es decir, triplicando el límite urbano. Este cambio permite pronosticar que la línea de crecimiento seguirá su tendencia horizontal, antes que en altura. Los nuevos sectores habitacionales que se han consolidado y se siguen construyendo, mantienen esta lógica expansiva.

Los factores anteriormente señalados a saber: el aumento poblacional, la expansión urbana y el terremoto no solo han cambiado la apariencia del casco antiguo de la ciudad -aún en ruinas-, sino que también han favorecido una serie de cambios en el transporte y la movilidad de la población. Algunas de las manifestaciones principales son la mayor dificultad de acceder al centro desde las nuevas periferias -zonas de mayor densidad demográfica donde viven sectores de menor ingreso- y la mayor demanda por transporte público, que a la larga y frente a la inversión pública siempre limitada y reactiva, pone al límite la capacidad de carga de la infraestructura vial. El ministerio ya vislumbraba esta situación el 2007, señalando que las principales vías de acceso, especialmente en el sector norte presentarían serias deficiencias. Lo mismo ocurriría con la zona de Maule (sector sur), debido a la baja conectividad y la gran proyección de viviendas destinadas a esa zona, provocando una conurbación no planificada (MINVU, 2007).

Lamentablemente cuando se busca ver cómo estos fenómenos urbanos se relacionan con la forma en que se producen los desplazamientos cotidianos en la ciudad, los datos son escasos y desactualizados. La última Encuesta Origen Destino, publicada el 2004, es útil para conocer la distribución de viajes según tipo de vehículo:

Figura $\mathrm{N}^{\circ} 2$

Viajes según modo de transporte
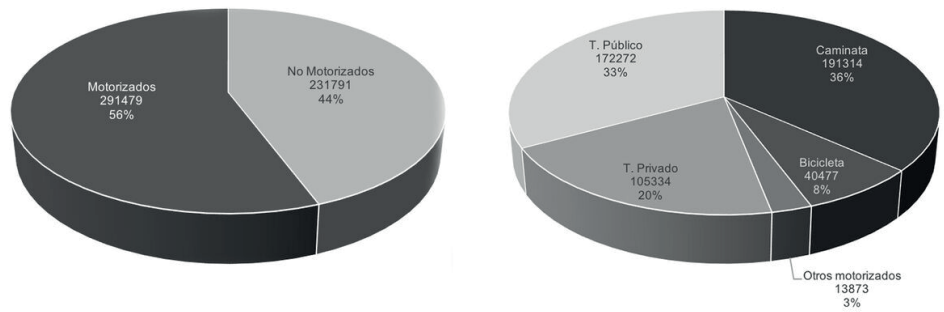

Fuente: Encuesta Origen-destino Talca, 2004.

Los datos muestran que en el año 2003 los modos motorizados y no motorizados representaban casi el mismo porcentaje de los viajes totales, mientras que la caminata era el medio de movilización que más se utilizaba (Figura $N^{\circ} 2$ ). El problema de esta encuesta, es que no da cuenta de los cambios que fueron descritos más arriba, ya que estos comenzaron a desarrollarse con más fuerza desde el 2005 en adelante.

La poca actualización que tienen los estudios acerca del transporte y sus correspondientes planes de ejecución no hacen posible realizar una comparación exacta, empero es posible ir delineando algunos puntos de contraste si se busca en otro tipo de fuentes. El parque automotriz, que representaba un $20 \%$ de los viajes totales en el año de la encuesta, ha crecido considerablemente en la última década, siendo uno de los factores que más ha influido en la transformación de la ciudad. Las Figuras $\mathrm{N}^{\circ} 3 a$ y $3 \mathrm{~b}$ muestran el importante aumento del parque de vehículos mo- 
torizados, prácticamente siendo equivalente a la totalidad del crecimiento de vehículos, mientras que el aumento de los no motorizados es muy marginal y casi imperceptible.

Figura $\mathrm{N}^{\circ} 3$

Aumento del parque de vehículos motorizados comuna de talca 2000-2013

(a)

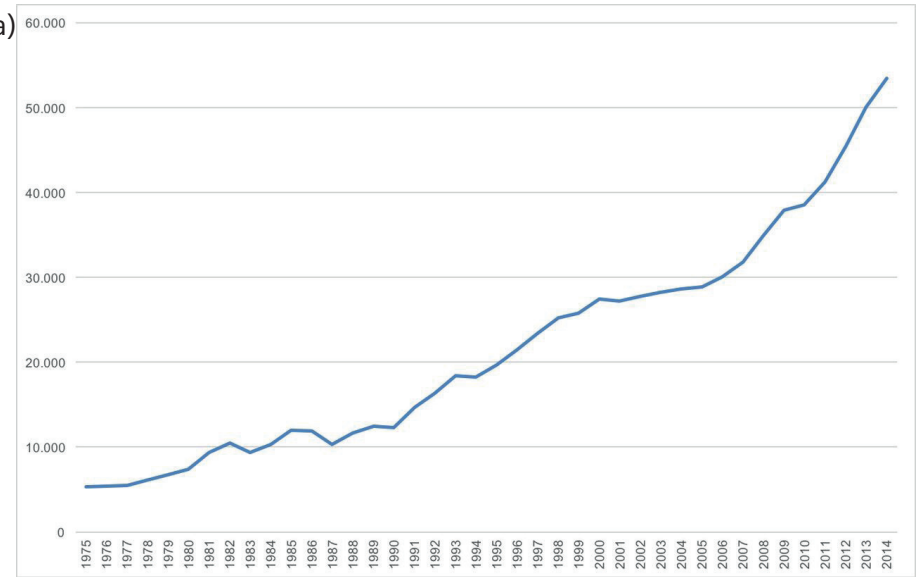

(b)

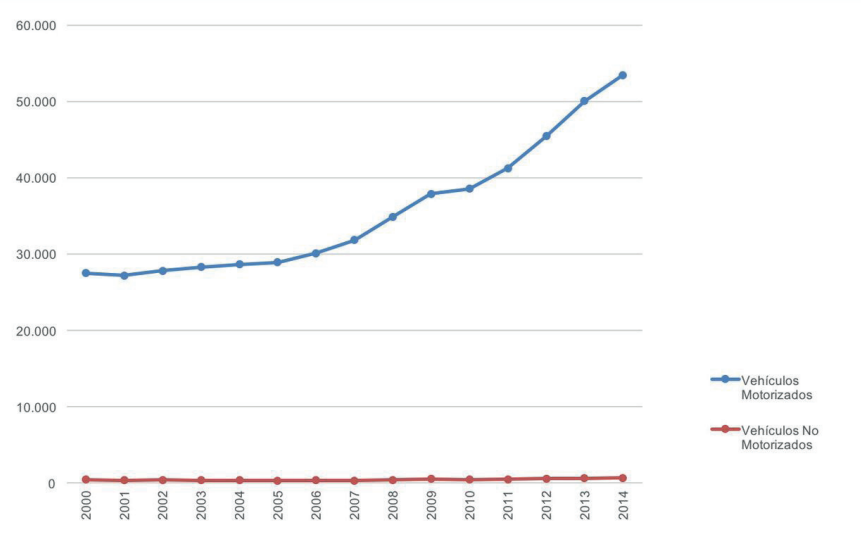

Fuente: Elaboración propia basado en datos de INE, 2014

Durante el período 2006-2013 es cuando se observa el mayor aumento, pasando de cerca de 30.000 vehículos a casi 50.000 en tan solo 6 años. Si ahora se pone atención a cuáles fueron los vehículos motorizados que presentaron un aumento más sustancial, los más notables son Automóviles/Station alcanzando en 2013 un total de 30.000, lo que significa que dentro del período indicado prácticamente se duplicaron, presentando un crecimiento anual promedio de 7,7\% (Figura $\left.N^{\circ} 4\right)$. Según datos del INE, la ciudad de Talca se encuentra debajo solo de Curicó que presenta un crecimiento promedio anual de 9,2\% y Concepción con un 9,1\% en este tipo de vehículos. Luego, le sigue Rancagua con un $7,3 \%$; Valdivia con $6,8 \%$; Iquique y Temuco con un $6 \%$; Santiago con un $5,9 \%$ y finalmente Valparaíso, con un $4,5 \%$. Las motocicletas por su parte, se quintuplican, aunque aún no alcanzan los volúmenes que se observan en automóviles y camionetas. Los microbuses y 
taxi-colectivos en cambio, se han mantenido o bien han decaído durante los últimos años (Figura $N^{\circ} 5$.

Figura $\mathrm{N}^{\circ} 4$

Crecimiento de vehículos motorizados, automóviles y camionetas en la comuna de Talca entre 2006 y 2013

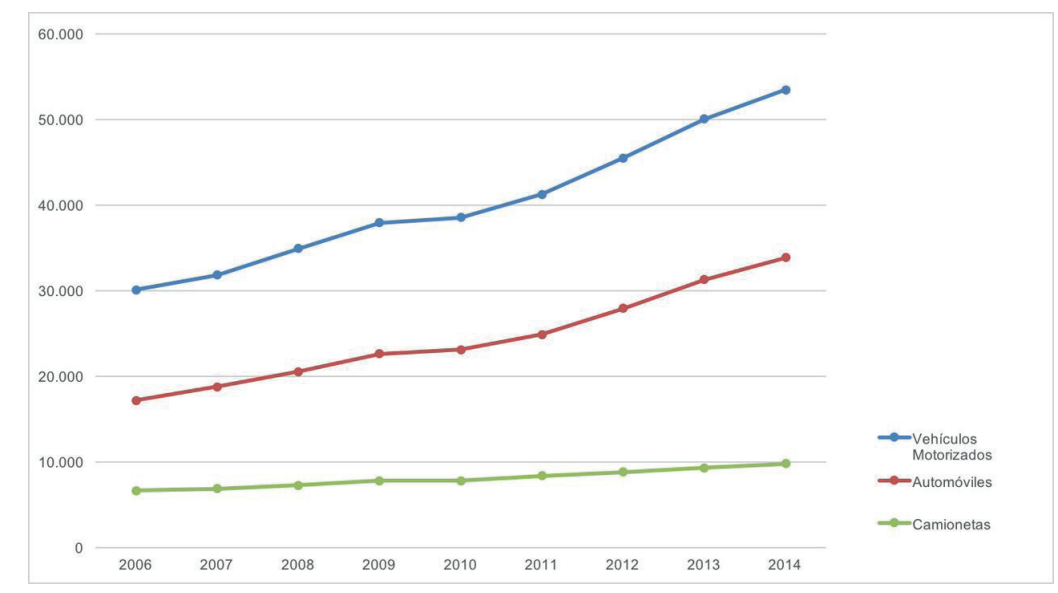

Fuente: Elaboración propia a partir de datos del INE, 2014

Figura $\mathrm{N}^{\circ} 5$

Total de Motocicletas, taxi-colectivos y micros en la comuna de Talca 2006-2013

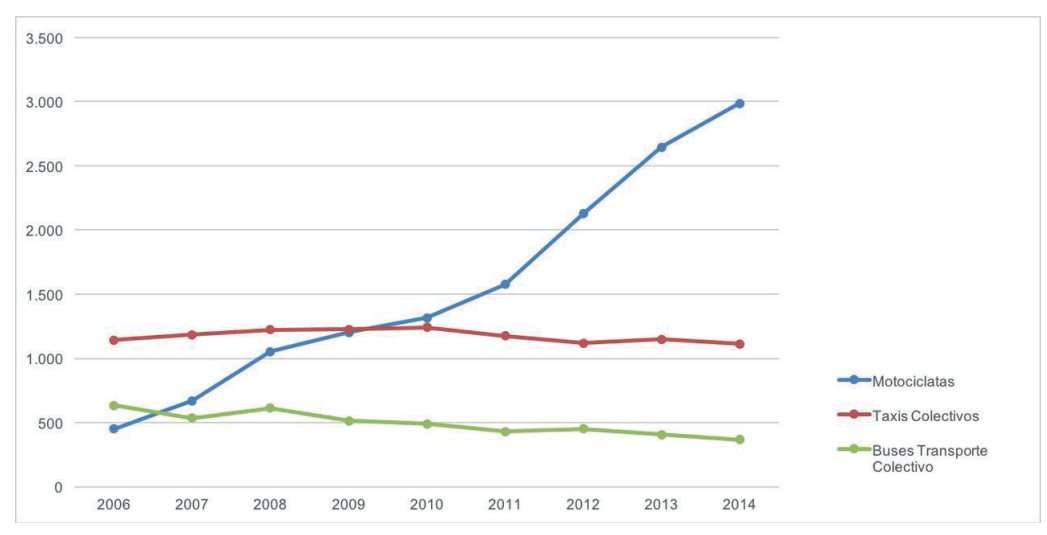

Fuente: Elaboración propia a partir de datos del INE, 2014.

El aumento significativo en los viajes privados sobre vehículos motorizados responde, por un lado, al hecho de que gran parte de la población de la ciudad, ante el incremento de los viajes centro-periferia, buscó acceder a la ciudad a través de un vehículo particular, mejorando así las capacidades de traslado propias o de sus familias. Por otro lado, también se deben considerar como factores influyentes la masificación de la oferta de automóviles, la ampliación de las formas de pago mediante créditos y convenios, y el impacto de la publicidad que ha permeado la opinión pública, instalando al automóvil como un símbolo de status y diferenciación social (Sanz, 1996). 
Para el caso de Talca, la conjunción de estos factores provocó un aumento sin precedentes del parque automotriz. Tal como se expresa en el Cuadro $N^{\circ}$ 1, se puede apreciar que en 2006 el 76,4\% de las familias talquinas no poseían un automóvil de uso particular, mientras que en el 2013 es sólo el $7,4 \%$ de estas quienes no poseen y es cerca del $92 \%$ quienes tienen al menos un automóvil.

\section{Cuadro $\mathrm{N}^{\circ} 1$}

Porcentaje de familias que poseen vehículos en uso y funcionamiento

\begin{tabular}{|l|r|}
\hline \multicolumn{2}{|c|}{ Año 2006 } \\
\hline Número de vehículos en uso y Funcionamiento & \multicolumn{1}{r|}{ Porcentaje } \\
\hline O vehículo & $76,4 \%$ \\
\hline 1 Vehículo & $22,7 \%$ \\
\hline 2 Vehículos & $0,9 \%$ \\
\hline Año 2013 & Porcentaje \\
\hline Número de vehículos en uso y Funcionamiento & $7,4 \%$ \\
\hline O Vehículo & $77,8 \%$ \\
\hline 1 Vehículo & $14,4 \%$ \\
\hline 2 Vehículos & $0,03 \%$ \\
\hline 3 Vehículos & \\
\hline
\end{tabular}

Fuente: Elaboración Propia en base a CASEN 2006 y CASEN 2013

La masiva presencia de vehículos motorizados entre los años señalados, refleja, por una parte, la necesidad de los habitantes, de obtener formas de acceso a la ciudad más efectivas, atendiendo a las transformaciones urbanas ya señaladas. Por otra, implica también nuevas dificultades como la congestión vehicular, el aumento en los tiempos de viaje y una mayor contaminación. Ante tales dificultades, desde la década del 2000 se vuelven más frecuentes proyectos de renovación vial, que prometen formas de desplazamiento más eficientes y modernas. Proyectos como una circunvalación, la ampliación de diversas arterias y la construcción de nuevos pasos de nivel (Figura $\mathrm{N}^{\circ}$ 6) fueron algunos de los más notables cambios que se vivieron en la ciudad, relativos al tema de la infraestructura y la conectividad. Pese a ello, estos proyectos viales han privilegiado el uso de vehículos a motor por sobre la movilidad no motorizada, lo cual podría asociarse a un posible decrecimiento de este tipo de desplazamientos entre el 2003 (año de la última EOD) y la actualidad $^{4}$.

A pesar de que las personas entrevistadas vean con buenos ojos los esfuerzos que se han hecho en pos de reducir la congestión en horarios punta y que la renovación de la infraestructura vial ha sido un avance, piensan que es todavía insuficiente, ya que el problema aún persiste: "Abren una calle nueva o ampliación de calle nueva, funciona bien dos tres días y después ya está saturado..." (Automovilista, sector Oriente). Las nuevas avenidas por su parte, al fomentar el uso

Lamentablemente, no es posible medir con exactitud cuánto han disminuido este tipo de desplazamientos, por lo que se menciona solo como una hipótesis a tener en cuenta. 
Figura $\mathrm{N}^{\circ} 6$

Sectores de Talca que presentan renovación vial post terremoto

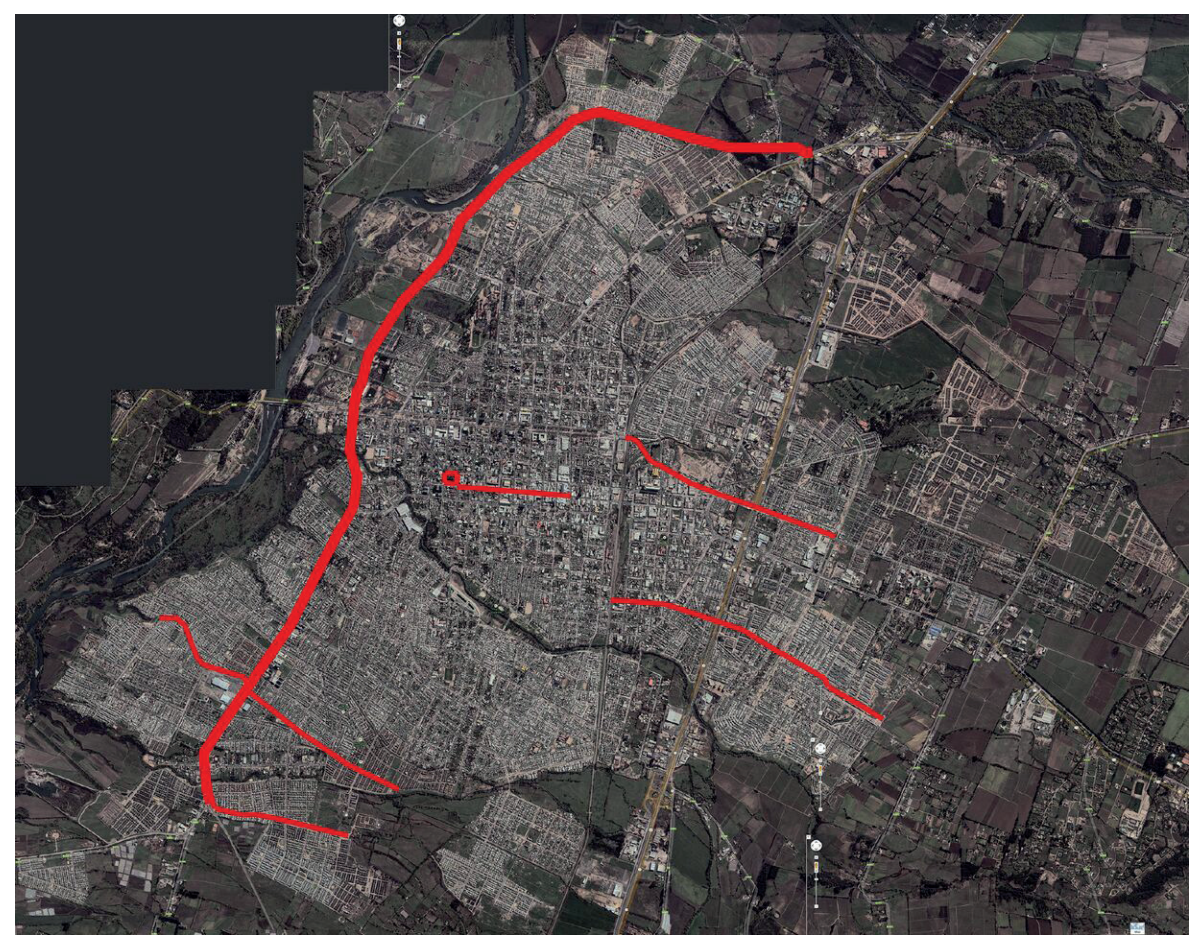

Fuente: Elaboración propia.

del automóvil, contribuyen a seguir llenando la ciudad de vehículos particulares, dificultando aún más el traslado en horarios de mayor afluencia y convirtiendo las vías de acceso en estacionamientos, puesto que la ciudad no cuenta con los espacios suficientes para tales efectos.

\section{Experiencias de movilidad e imaginarios urbanos}

Variables objetivables y medibles como el aumento poblacional, la expansión urbana y los daños provocados por el terremoto; y más específicamente aquellas vinculadas a la movilidad de personas en Talca como el significativo aumento del parque de vehículos motorizados e infraestructura vial, generan un entorno urbano distinto. Este nuevo escenario que los entrevistados confirman a través de sus testimonios, conlleva nuevas experiencias urbanas que en muchos sentidos cuestionan y quiebran con las prácticas tradicionales asociadas a la ciudad. En otras palabras, con los cambios en el entorno material se transforma también la ciudad percibida y representada.

Las distintas formas de movilización no solo repercuten en el tipo de interacciones sociales que se desarrollan entre individuos (Amin, 2008; Mattioli, 2014), sino que también ha modificado la manera en que estos se relacionan con la ciudad en su conjunto. El modo de viaje, define en gran medida, el lugar que corresponde durante los traslados y ello implica que los recorridos en 
bicicleta, en micro, en auto o a pie, posicionan al individuo desde diversos puntos de vista para contemplar y vivenciar la ciudad (Spinney, 2006; Pierce, 2012; Errázuriz, 2012; Fallov et al., 2013). Tal como señala Cresswell (2010) la movilidad no es sólo "movimiento" de un lugar a otro, bajo ciertas condiciones de ritmo, velocidad, distancia y frecuencia, ubicables y medibles, sino que también es motivo de representaciones bajo las cuales se congregan significados y narrativas diversas que pueden promover ideas de libertad, ocio o progreso; y a la vez es también un conjunto de prácticas que se experimentan de manera diferenciada según cada persona y su realidad particular.

Mientras la encuesta y la información estadística han sido las fuentes privilegiadas cuando se busca comprender la movilidad exclusivamente como desplazamiento, la aproximación etnográfica es imprescindible si lo que se busca es ahondar en las representaciones y prácticas que también conforman esta movilidad. Este fue el foco de 25 entrevistas realizadas a diferentes personas de la ciudad Talca, a partir de una muestra acorde a los sectores definidos en base a la última encuesta origen destino (SECTRA, 2004) y poniendo énfasis en los distintos modos de viaje que cada uno de ellos utiliza mayoritariamente. Si bien es claro que no existen personas que solo utilicen un modo de viaje, sí es posible definir en la mayoría de los entrevistados una clara tendencia hacia una forma de movilización particular.

Cuadro $\mathrm{N}^{\circ} 2$

Distribución muestral de entrevistas por sector

\begin{tabular}{|l|r|r|r|r|r|r|}
\hline & $\begin{array}{c}\text { Fuera de } \\
\text { Talca }\end{array}$ & \multicolumn{1}{|c|}{$\begin{array}{c}\text { Sector } \\
\text { Norte }\end{array}$} & $\begin{array}{l}\text { Sector Sur- } \\
\text { poniente }\end{array}$ & Centro & $\begin{array}{l}\text { Sector } \\
\text { oriente }\end{array}$ & Total \\
\hline Bicicleta & 0 & 2 & 1 & 0 & 2 & 5 \\
\hline Automóvil & 1 & 1 & 3 & 0 & 2 & 7 \\
\hline Transporte público & 3 & 2 & 3 & 1 & 2 & 11 \\
\hline Peatones & 0 & 0 & 0 & 2 & 0 & 2 \\
\hline Total & 4 & 5 & 7 & 3 & 6 & 25 \\
\hline
\end{tabular}

Fuente: Elaboración propia

Mediante la aplicación de una entrevista semi-estructurada, se buscó conocer e indagar en aquellos significados que los entrevistados asocian a su movilidad cotidiana. Al mismo tiempo, se utilizó un mapa de la ciudad, mediante el cual el entrevistado podía ir trazando sus recorridos más frecuentes, e identificando espacios y lugares significativos. Posteriormente todo el material georreferenciable fue digitalizado en Google Earth. A partir de esta metodología, los entrevistados pudieron trazar en el mapa sus rutas cotidianas actuales e históricas, pudiendo obtener información no solo relativa a distancias y tiempos promedio de viaje, sino que además se pudo conocer las formas que adquieren dichas rutas. A partir de tales trazados (Figura $\mathrm{N}^{\circ} 7$ ) fue posible identificar algunos rasgos representativos de cada modo de viaje, siendo elementos constitutivos de su experiencia de movilidad y sus imágenes de la ciudad.

Desde una aproximación morfológica, se puede concluir que la trama de las rutas en bicicleta y a pie, son más enmarañadas que la que se forman con los flujos en automóvil. Si bien, en los casos en que es posible desarrollar una ruta personalizada (peatones, ciclistas y conductores), los 
Figura $\mathrm{N}^{\circ} 7$

Ejemplo de trazados de las entrevistas de movilidad cotidiana

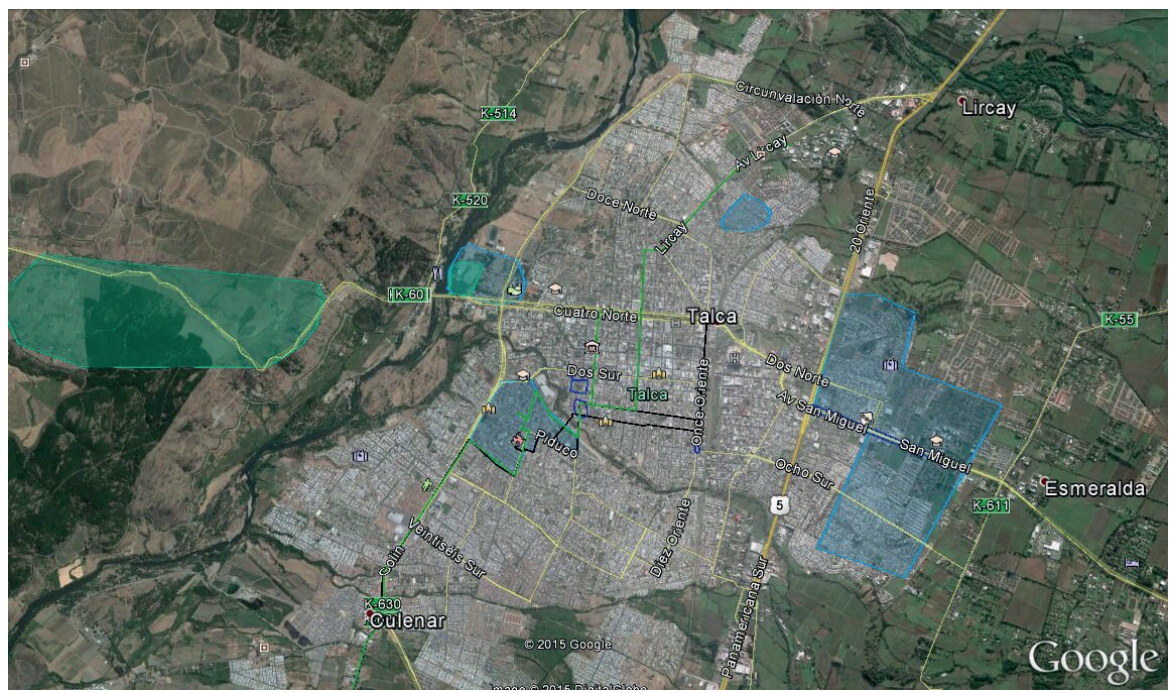

Fuente: Elaboración Propia

conductores prefieren calles extensas que les permitan desplazarse en línea recta, alcanzando mayor velocidad. En cambio, los ciclistas con el afán de evitar los lugares más transitados toman pasajes, calles estrechas o la calle de servicio de la carretera. Por su parte, el transporte público recorre las principales arterias y sus recorridos son bastante funcionales mientras se encuentran en el área central. Sin embargo, en la medida en que se alejan hacia la periferia, las micros se limitan a las calles principales, mientras que los colectivos se internan en los barrios llegando a sectores eminentemente residenciales.

Ahora bien, cuando se analizan las representaciones y prácticas asociadas a estas rutas aparecen una serie de otros componentes del viaje que van cualificando y diferenciando los distintos modos de trasladarse. Se observa así, que las personas que acostumbran a caminar por la ciudad viven relativamente cerca del centro. La ciudad que ellos dicen conocer es bastante íntima y cercana, muestran una mayor frecuencia de interacciones con las personas que se cruzan durante el trayecto y un conocimiento más acabado y cercano de los edificios, casas, barrios y personas, por los que pasan en su camino entre sus casas y su destino.

Por su parte, los automovilistas entrevistados, tienden a atravesar por fuera las zonas residenciales, salvo en algunos contados casos en que se usen atajos para partes del trayecto. La velocidad de los desplazamientos, la distancia recorrida, las dificultades para detenerse y las condiciones de aislamiento que genera el vehículo, promueven formas de conocimiento más amplias y generalizantes, que proporciona una posición de espectador de las transformaciones que sufre la urbe. Rara vez el automovilista refiere a formas de conocimiento específico sobre los lugares que recorre.

Quienes utilizan la locomoción colectiva, son quienes a través de sus traslados se insertan de una manera mucho menos profunda en los sectores residenciales y tranquilos, debido a que el 
recorrido funcional de su modo de viaje, por lo general no se enmarca en esos sitios. Recorren las principales arterias del centro, pero delegando la conducción a un tercero, lo cual los posiciona como actores pasivos del recorrido, permitiéndoles realizar algunas actividades como escuchar música, estudiar o dormir.

Finalmente, están los ciclistas que, en cierta forma, se ubican entre el peatón y el automovilista: por una parte, desarrollan un mayor contacto con la ciudad, utilizan vías que atraviesan por los barrios y se separan del centro, así como también cruzan la ciudad a una cierta velocidad, lo que implica que su mirada sea mucho menos minuciosa que la desarrollada a pie. En ese sentido, el ciclista podría ubicarse en una interfaz entre espectador y participante de las dinámicas de la ciudad.

Figura $N^{\circ} 8$

Superposición de las rutas habituales de los 25 entrevistados

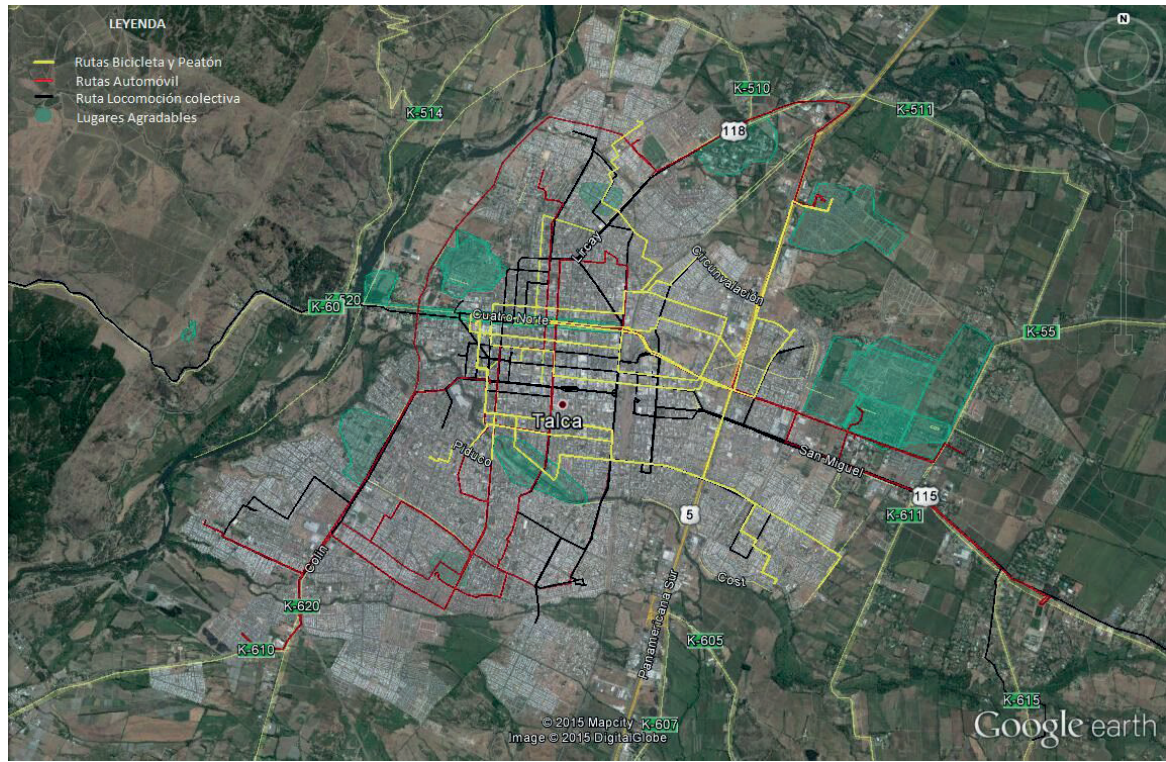

Fuente: Elaboración propia.

Lo interesante de descubrir qué ciudad se va conociendo, a través de la ruta elegida y practicada a diario (Figura $\mathrm{N}^{\circ} 8$ ), es que a partir de estas experiencias los sujetos van identificando ciertos elementos de la ciudad que, de manera fragmentaria, constituyen imágenes de esta, las cuales se superponen, se organizan y permiten al actor comprender y actuar sobre ella. Cuando un sujeto habita y actúa dentro de su entorno, lo hace desde una visión particular, a partir de un imaginario ya instituido, pero al mismo tiempo produce, mediante su propia interpretación un imaginario radical o instituyente (Castoriadis, 1993). Este imaginario radical puede cuestionar o transformar a los imaginarios instituidos, generando nuevas interpretaciones que, a su vez, pueden institucionalizarse dentro de la sociedad. La "ciudad vivida" o las prácticas que animan la vida urbana estarían asociada a la construcción de ciertos imaginarios, que permitirían apropiarse del espacio urbano, organizarlo y valorizarlo para así poder habitarlo (Hiernaux, 2007). Asimismo, estos imaginarios se traducirían en estrategias y acciones concretas de los habitantes sobre la ciudad, motivadas por las motivaciones personales (Hiernaux, 2007). 
El cruce de las experiencias de viaje cotidianos de los habitantes de una ciudad como sustento para la construcción, validación y reconfiguración de imaginarios urbanos (García Canclini, 1996), es un proceso que también se puede distinguir desde los testimonios de los entrevistados. A partir de estas experiencias cotidianas los residentes de la ciudad van coleccionando un sinnumero de imágenes no siempre coherentes en sus significantes, pero que funcionan de todos modos como fragmentos de una imagen mayor de ciudad. Estos fragmentos se conectan y adquieren sentido en la medida en que se asocian a esquemas asimilados previamente que funcionan como "matrices de comprensión" (Hiernaux, 2007).

Si bien son numerosas y variadas las imágenes y discursos asociados a Talca que se desprenden de los relatos de los viajeros, al colocar estos relatos en perspectiva histórica o contrastándolos por medios de movilización, es posible identificar la preeminencia de dos imaginarios de ciudad muy distintos, que presentan continuidades, rupturas y tensiones entre sí. Siguiendo las ideas de Lindón (2007) estos imaginarios constituyen una trama de sentido y no serían otra cosa que subjetividades compartidas que darían forma y cualificarían un espacio social en constante construcción y siempre inconcluso.

Esta mutabilidad constante de los imaginarios en cuestión se inserta en un contexto histórico, que en este caso específico se distingue por la intensificación de los procesos modernizadores sobre territorios donde aun persisten con fuerza formas y estructuras tradicionales. Con la multiplicación del parque vehicular motorizado, la modernización de la infraestructura vial, el crecimiento del área urbana y del número de habitantes, entre otros, los entrevistados reconocen con claridad una nueva experiencia del viaje e idea de ciudad que se contrapone violentamente a los recuerdos que tenían de sus viajes en esta misma ciudad, diez años atrás. A la nueva ciudad la llamaremos ciudad "horario punta" y se la reconoce como una ciudad de corta data, donde prevalecen los tacos, la congestión, los viajes largos y agotadores; una ciudad de tensiones, de mayor número de accidentes e incertidumbres.

Este imaginario de ciudad, que se asocia directamente al proceso de modernización y cuyo referente más claro proviene de Santiago, coexiste diariamente con el mismo imaginario con que se enfrenta, al que llamaremos el de ciudad "horario valle". Este último corresponde a ese Talca tranquilo, pequeño, sin inconvenientes, ni sorpresas, donde los viajes toman poco tiempo, son placenteros y se realizan entre conocidos. Ambos imaginarios son en cierta medida deseados y rechazados. Se quiere una ciudad nueva y moderna, pero también se desea mantener los tiempos de viaje de siempre. Se añora la tranquilidad del Talca acotado y conocido, pero ya muchos quieren vivir en las afueras y tener un automóvil. Sin la claridad de una definición, hoy Talca pareciera alternar aceleradamente entre una ciudad de horarios valle y horarios punta, más esquizofrénica que la capital, debido a que las distancias parecen más intensas y porque no son dos sino cuatro puntas al día.

\section{La ciudad "horario Valle"}

En una ciudad como Talca, las experiencias de movilidad en primera instancia, parecieran bastante menos agotadoras si se comparan con otros estudios centrados en la metrópoli (Muñoz, 2013). Los mismos entrevistados dan cuenta de ello. El tamaño de la ciudad y su cantidad de habitantes no tiene comparación con la capital y en ese sentido, la opinión general acerca del viaje cotidiano, valora esa brecha. En una ciudad donde la mayor parte de los trayectos fluctúa entre 
los 15 a 20 minutos en promedio -tiempo soñado en ciudades como Santiago- no es de extrañar que los viajeros no les dediquen demasiada importancia y preocupación a sus traslados en sus rutinas cotidianas.

"Es que no se me hace caos, no, no me produce esa angustia como cuando estoy en Santiago que terrible la hora peak y tengo que hacerme aplastar y que voy más o menos en el aire y me lleva la gente adentro del metro y que tengo que hacer el transbordo y hay millones de persona... eso aquí felizmente no, entonces no me angustia" (Usuaria de locomoción colectiva, Sector Norte).

Más aún, la mayoría de los entrevistados aseguraron no realizar alguna actividad específica durante sus tiempos de viaje, salvo algunos jóvenes y automovilistas que escuchaban música o radio. Cuando se tiene que la distancia promedio de los viajes realizados por los entrevistados es de 5,4 km. se refuerza la idea de que, a simple vista, el viaje cotidiano dentro de la ciudad es bastante poco problemático. Cuando se vive fuera de la ciudad en cambio, fue posible detectar actividades como leer, estudiar o dormir.

Pasando por distintos testimonios de viajeros, es posible reconocer la existencia de un imaginario ampliamente compartido asociado a una ciudad pequeña, anterior. Se trata de una ciudad que conserva algo de pueblo, un lugar con historia donde las personas se sienten cercanas unas de otras; una ciudad con muchos menos traslados en vehículos motorizados; de caminos de tierra, gente caminando, bicicletas y carretas. La Ciudad Horario Valle destaca por su tranquilidad y su seguridad, es un lugar donde los niños comparten en la calle, en el pasaje con el anciano que se sienta en la banqueta. Una ciudad en donde aún existe la confianza del barrio viejo, donde no es necesario dejar los portones con candado cuando hay un vecino de buena voluntad que se preocupe del pasaje.

"Entonces, eso es como lo bueno que hay, porque es como gente ya más de edad y los niños en sí comparten como a la antigua, salen a jugar a la pelota, al trompo..." (Automovilista, Sector Norte).

La tranquilidad es el elemento central que distingue a la Ciudad Horario Valle, asociado fuertemente a sus sectores residenciales. Esta tranquilidad empero, encierra una doble significación: por una parte, es seguridad, por otro es sinónimo de lentitud, de aburrimiento. Aquí el tiempo transcurre sin mayores agitaciones, resistiéndose a entrar en el intenso caudal de la modernidad. Los entrevistados, en ese sentido, dan cuenta de la "lentitud" con la que se vive en muchas ocasiones $y$, sin embargo, son conscientes de que aquello representa una ventaja:

“Prácticamente llevo 17 años aquí, entonces uno igual lo lleva con orgullo lo que tiene, aparte que esa no es la gran virtud ni el valor de Talca, el valor agregado de Talca es que es un lugar tranquilo pa vivir poh, que es de bajo costo, donde no es tan bohemio, que viví tranquilo sin grandes gastos económicos, el pan por ejemplo en otros lados es súper caro..." (Automovilista. Sector Oriente).

En la Ciudad horario Valle ocurren situaciones que contradicen los problemas expresados anteriormente: los habitantes aún conservan la costumbre de regresar a sus hogares para almorzar en familia (CEUT, 2014), aunque ello implique que se genere otro horario punta a medio día. De 
igual forma, consideran que la dependencia existente con el centro es bastante positiva, pese a que en muchas ocasiones esto provoque serias dificultades de acceso a este sector:

"Uno llega al centro y no se sube a una micro hasta cuando terminó de hacer 20 cosas, eso es fantástico, es una facilidad enorme, imagínese en Santiago uno va a un lado a hacer un trámite, después tiene que pasar todo Santiago para ir a otro lado y con el mismo trámite porque está relacionado". (Usuaria locomoción colectiva. Sector Sur-poniente).

Sea en el centro como en los barrios, subsiste una forma de movilizarse que todavía no logra ser desplazada completamente por el avance de los motores y el crecimiento urbano y que es muy valorada por sus habitantes. La virtud que tiene esta ciudad horario valle, aunque se la tilde de lenta y aburrida, encierra en su interior la comodidad de una vida tranquila, delimitada, donde existe todavía el tiempo para relacionarse con los vecinos y tener todo lo necesario más o menos al alcance. Es este el imaginario urbano que fue posible conocer en las formas de sociabilidad en movimiento que aún desarrollan muchos ciclistas y peatones. Aunque no es monopolio de estos. También es parte de la vida de quienes, si bien usan automóvil o transporte público, aún caminan todos los días por su barrio y prefieren comprar en el almacén antes que en el supermercado (CEUT, 2014).

La Ciudad Horario Valle, finalmente, encierra una doble lectura: es a la vez, un largo "Horario Valle" mirado con los ojos del viajero habitual del metro capitalino; y una forma particular de habitar (De Certeau, 2000) que discurre en ciudades típicas del Valle Central de Chile y que descansa, en parte, sobre sus rasgos morfológicos. Basta con observar los $8 \mathrm{~km}$ de diámetro de la zona urbana de Talca y la ausencia de desniveles considerables, lo que la hace una ciudad privilegiada para el uso de formas no motorizadas de desplazamiento.

\section{La ciudad "horario Punta"}

Tal como se describía anteriormente, durante las últimas décadas esta Ciudad Horario Valle ha experimentado una serie de transformaciones que comienzan a afectar no sólo el entorno material, sino además los ritmos urbanos. Uno de los factores que más destacan los entrevistados es el notorio cambio que existe durante los horarios punta. Pese a que en un principio fue posible apreciar que el viaje cotidiano no representa mayores problemas para los talquinos, durante los horarios de mayor afluencia esta idea se ve claramente cuestionada. En este horario, todo se agita de tal manera que Talca se asemeja mucho más a una metrópoli que a la ciudad tranquila de provincia. Los flujos vehiculares, los tacos, el ruido y la violencia en la ruta son los rasgos más comunes para quienes deben enfrentarlo a diario. Cabe señalar, que según el vehículo que se utilice, existen también diferencias en cómo se perciben estos momentos del día. Quienes toman la locomoción colectiva son los más afectados, debido a la incomodidad que significa el desplazarse por largo rato en una micro o colectivo repleto de pasajeros. Lo anterior también implica que muchas personas se queden abajo del transporte y deban esperar largos intervalos para poder dirigirse a sus destinos. Para ellos, el horario punta también es sinónimo de inmovilidad y frustración. Otros con más suerte, desarrollan algunas formas alternativas de evitar estas complicaciones.

“La micro pasa como a las siete, pero jamás la ocupo en la mañana... porque vienen llenas, no paran, están todas congestionadas. O sea, mi papá va a dejar a mi hermana al liceo y ahí me lleva para la U." (Usuario locomoción colectiva, sector oriente). 
Las personas que utilizan el automóvil particular, reclaman acerca del lento tránsito que se vive durante estos períodos en ciertos sectores de la ciudad, obligándolos a salir más temprano de sus hogares, tomar rutas alternativas o simplemente esperar. Aquí en ningún caso se considera la posibilidad de utilizar el transporte público como medio alternativo de viaje con tal de hacer más expedito el traslado, pues se sabe que la situación es peor en ese tipo de vehículos.

“Por la 25, pero viene llena. Mi hermana trabaja y se va en micro, entra a las 8, y tiene que salir de aquí como a las 7 para poder llegar a la hora, porque las micros vienen llenas, llenas. Y yo por eso opté por la opción de comprarme el autito, porque realmente quedaba botada. No tomaba locomoción, así no tenía que caminar por la 25 hasta allá, hasta cerca de tu casa a tomar la micro". (Automovilista, sector Sur Poniente).

La ciudad horario punta requiere previsión, cálculo y planificación estratégica. Los tiempos enlentecidos de desplazamiento y las condiciones de incertidumbre en que se realizan estos viajes, obligan a los viajeros a considerar alternativas de viaje, improvisar frente a situaciones inesperadas o en último caso, a esperar y practicar la paciencia.

El mapa de la Figura $N^{\circ} 9$ muestra todas aquellas áreas de la ciudad que fueron identificadas por los entrevistados como lugares donde regularmente se producen tacos y atochamientos durante los horarios de mayor tráfico. La ciudad punta no es toda la ciudad, sino que se concentra en las arterias principales del tránsito, especialmente en las vías del transporte colectivo. Son las mismas calles que permiten sortear las barreras naturales y construidas (especialmente el camino longitudinal y la línea del ferrocarril), conectando el centro histórico con los barrios residenciales que han ido creciendo hacia la periferia. Esta concentración en unas pocas calles intensifica la sensación de congestión para quienes circulan en ellas, mientras las restantes más bien refieren a la ciudad horario valle. De aquí se desprende que quienes utilicen los medios no motorizados tengan una experiencia distinta de la ciudad en los horarios de mayor tráfico. Este fue el foco de un ensayo audiovisual que buscaba probar como la ciudad horario punta y la ciudad horario valle conviven simultáneamente en una misma área. El ensayo consideraba tomas de un minuto en dos calles paralelas del centro realizadas durante la hora punta. Mientras la calle 2 Norte -que cruza la línea del ferrocarril y concentra toda la circulación de colectivos- mostraba evidentes signos de congestión y atochamientos, la 3 Norte, que corre paralela a sólo una cuadra de distancia, se mostraba despejada y con algunos autos ocasionales.

Aunque los ciclistas no son afectados directamente por el tránsito lento y los tacos, pues pueden tomar calles menos transitadas, sí se sienten mucho más vulnerables e inseguros durante este horario. Esta sensación se agrava, ante el hecho de no poseer espacios adecuados para el uso de este medio, viéndose obligados a utilizar aceras y veredas no acondicionadas. Si bien existen ciclovías, éstas no han sido diseñadas con los estándares correspondientes y no funcionan como una red vial alternativa a las del transporte motorizado. Finalmente, en el caso de los individuos que se desplazan caminando, este horario no reviste un mayor problema, salvo en términos de la inseguridad que significa para el peatón el aumento de los viajes motorizados.

En oposición a la Ciudad Horario Valle, la Ciudad Horario Punta se aleja del recuerdo de la tranquilidad provinciana, para acercarse a las dinámicas de la metrópoli, aquella ciudad de los flujos frenéticos, de la incomodidad para quienes no pueden acceder a un automóvil, de la incertidumbre y del tiempo detenido en el espacio. 
Figura $\mathrm{N}^{\circ} 9$

Trazado de sectores con problemas de movilidad, según las entrevistas realizadas

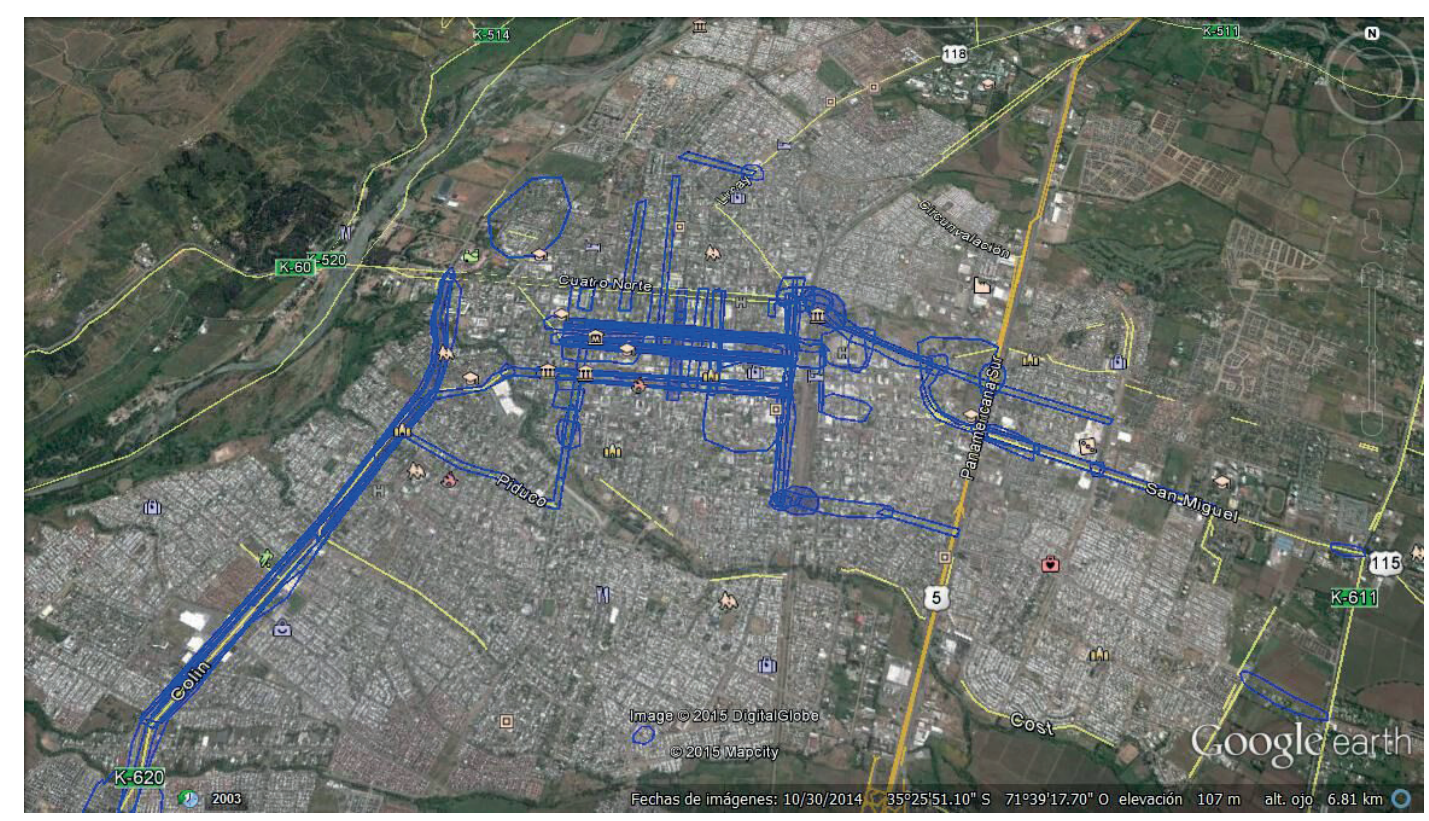

Fuente: Elaboración propia según información entregada por entrevistados.

La renovación vial que fomenta el uso del automóvil y los desplazamientos a alta velocidad, parecen ser una forma de cumplir cierto anhelo metropolitano que fue posible identificar en algunos entrevistados. De igual forma, la renovación urbana que sucedió al terremoto de 2010, fomentando la aparición de edificios en altura y centros comerciales, refuerzan la imagen de una ciudad que no pretende quedarse abajo del carro de la modernidad, aunque ésta sea solo de segunda mano. (Errázuriz y Valdés, 2017).

"La mejora fue después del terremoto, pero totalmente, gracias por los edificios, sobre todo el sector centro...ahora uno puede salir cualquier día, el día sábado, el día domingo y tú puedes ir a tomarte un helado, hay algo que uno puede ir a vitrinear si ahora, por ser ahora que hay trabajo el mismo hecho de querer salir a comprar algo, todo estaba cerrado, en esos tiempos, ahora no pos, tú sales el día sábado en la tarde y está abierto, el día domingo y está abierto, no todo pero está abierto, ese es un gran cambio digamos con el tiempo" (Peatón, sector centro).

La importancia que jugó la municipalidad, bajo el slogan Talca Renace, ha sido clave en este proceso de transformación. El mensaje que se buscaba transmitir era que Talca no solo renacía de las ruinas y escombros que había dejado el terremoto, sino también lo hacía con un nuevo rostro, más fresco y más urbano, en pos de sepultar las opiniones que históricamente la han 
tildado como ciudad aburrida y añeja. Es la ciudad que emula las dinámicas que se viven en la capital.

El imaginario de ciudad horario punta no está exento de tensiones y desavenencias. En esa línea, el proceso de reconstrucción y modernización urbana post terremoto ha generado bastante descontento en parte de los entrevistados, de acuerdo al poco interés de parte de las autoridades por recuperar y mantener el patrimonio histórico local.

“Lugares como el museo, el mercado debieran rescatarse, sí o sí, estructuras preciosas, antiguas que se han dejado ahí, tiradas. Entonces, yo creo que hay que hacer una combinación entre las dos [modernidad y conservación], no puedes olvidar las cosas bellas que hay del pasado, todo lo histórico, porque es parte de, como de la identidad de tu ciudad". (Automovilista, Sector Norte).

De igual manera, existe la consciencia entre este grupo de entrevistados de que, si sigue el patrón de crecimiento metropolitano, también se generarán otras dinámicas metropolitanas, mellando la tranquilidad, la seguridad y la cercanía destacada dentro del imaginario anterior. Un ejemplo de esta situación lo constituyen las nuevas áreas residenciales que en la última década han extendido el área urbana de Talca y que favorecen ciertas experiencias que distan de las formas de la vida de barrio tradicional que caracterizaban al centro.

"Es una villa nueva, entonces la verdad es que es muy distinto el ambiente. En cierta forma me ha sido difícil acostumbrarme porque en donde yo vivía antes tenía todos mis amigos de infancia, gente del alrededor y todo eso. Y ahí en la Villa Bicentenario donde vivo ahora es un sector con gente nueva, que no conozco. Es más que tiene otro tipo... a mí me ha sorprendido mucho el estilo de vida que tienen. Partiendo de que por falta de confianza y de tiempo no hay una fluidez vecinal muy fácil, porque prácticamente nadie se saluda..." (Ciclista, Sector Norte).

Estas nuevas experiencias de habitación, posibilitadas por el fortalecimiento del sector inmobiliario en una ciudad que hace décadas funciona bajo una lógica neoliberal (Letelier y Boyco, 2011), favorecen el avance del imaginario de ciudad horario punta por sobre el de horario valle. A diferencia de la configuración histórica de los barrios residenciales en este tipo de ciudades medias de base agrícola, estos desarrollos inmobiliarios generan áreas exclusivamente residenciales en las afueras de la ciudad, muchas veces con graves problemas de conectividad vial y deficiente acceso a transporte público. En vez de construir una trama en donde la caminata u otras formas no motorizadas sean una alternativa atractiva para acceder a una serie de servicios que antes se encontraban a corta distancia del hogar (educación, comercio, ocio, etc.), estos nuevos sectores exigen desplazamientos motorizados constantes para salir del aislamiento en que se encuentran. Entre los vehículos, el automóvil particular es señalado por la mayoría de quienes residen en estos lugares como el dispositivo indispensable para sobrellevar la complejidad que pueden adquirir los viajes cotidianos. En este sentido, no es posible entender el fuerte incremento que ha experimentado el parque automotriz en la última década en Talca si no se considera la proliferación de estos desarrollos inmobiliarios. 


\section{Motility/Mobility: una ciudad segregada}

El concepto motility (Kauffman y Flamm, 2006), permite comprender la movilidad no solo como los viajes efectuados, sino que además integra en ella las posibilidades que las condiciones territoriales y sociales proporcionan a los individuos. De igual modo, son los individuos quienes poseen la capacidad de elegir ciertos elementos y así definir su viaje a partir de los elementos más convenientes. Como puede imaginarse, las posibilidades no son iguales para todos y dependen mucho de factores como el barrio, los ingresos, la oferta de transportes, entre otros.

Siguiendo la lógica neoliberal que mueve los desarrollos inmobiliarios recién mencionados, es evidente que la situación de acceso y conectividad de las nuevas áreas residenciales no es homogénea. Si bien todos contribuyen a una mayor congestión y colaboran en la acentuación de los horarios punta, no es lo mismo para quienes se desplazan al centro en automóvil desde los sectores de alta renta, al nororiente de la ciudad, que para aquellos que dependen del transporte colectivo. La ciudad horario punta es una ciudad que tiende y promueve una diferenciación de las experiencias de viaje cotidiano, marcada por sus posibilidades de acceder a ciertos bienes (un auto, una casa bien localizada) así como las posibilidades de influir sobre el destino de los recursos públicos. El modelo capitalino de crecimiento urbano trae consigo una serie de consecuencias nefastas en el plano de la experiencia de movilidad, en el acceso a la ciudad y en la búsqueda de una ciudad más justa para sus habitantes. Los fenómenos de exclusión territorial (Cebollada, 2006) y fragmentación urbana (Jirón, 2014; Hidalgo, 2004) son solo algunos ejemplos de la larga lista de formas de desigualdad que se vive actualmente en la metrópoli, y que poco a poco comienzan a vislumbrarse en una ciudad como Talca.

Colaboran también en la construcción de esta ciudad horario punta, la creciente conectividad de Talca con otras localidades de la región del Maule. Posibilitados por la construcción y mejoramiento de los caminos interurbanos (Riveros, 2013) y crecimiento de la oferta de buses, Talca ha fortalecido su posición de capital regional que concentra servicios, educación, comercio y oportunidades laborales. Para quienes viven o trabajan en las afueras de Talca, el viaje cotidiano representa un tiempo significativo, asociado muchas veces a un conjunto de actividades, destacándose el tiempo para escuchar música, dormir una siesta o estudiar, en el caso de los jóvenes, que en algunos casos puede tomar hasta dos horas diarias. Es el caso de quienes se trasladan desde Linares y Curicó. Con mayor intensidad que en los desarrollos inmobiliarios de la periferia de la ciudad, los medios de movilización a los que se acceden se vuelven críticos en los tiempos y condiciones de estos viajes. Así, mientras quien viaja diariamente entre Talca y Curicó en automóvil puede demorar alrededor de 50 minutos de puerta a puerta, quien lo hace en bus podría tardar al menos 30 minutos más considerando los tiempos desde el terminal a los lugares de origen y destino.

Con respecto al transporte público, durante los últimos años se ha producido un aumento de la oferta de taxi-colectivos para intentar sobrellevar la fuerte demanda de transporte en las horas de mayor flujo. Pese a ello, existen bastantes diferencias entre las posibilidades de transporte que poseen determinados sectores de la ciudad. Por otro lado, los recorridos siguen orientándose, en su mayoría hacia el centro de la ciudad, de modo que no ha de sorprender que individuos que no trabajan en dicho sector no tengan la posibilidad de un medio de locomoción directo, debiendo recurrir a un transbordo que duplica el costo del viaje. Las Figuras $\mathrm{N}^{\circ} 10$ y $\mathrm{N}^{\circ} 11$ demuestran las diferencias que tienen 2 individuos de dos barrios adyacentes respecto del transporte público. 
Figura $\mathrm{N}^{\circ} 10$

Mapa de oferta de locomoción sector El Tabaco

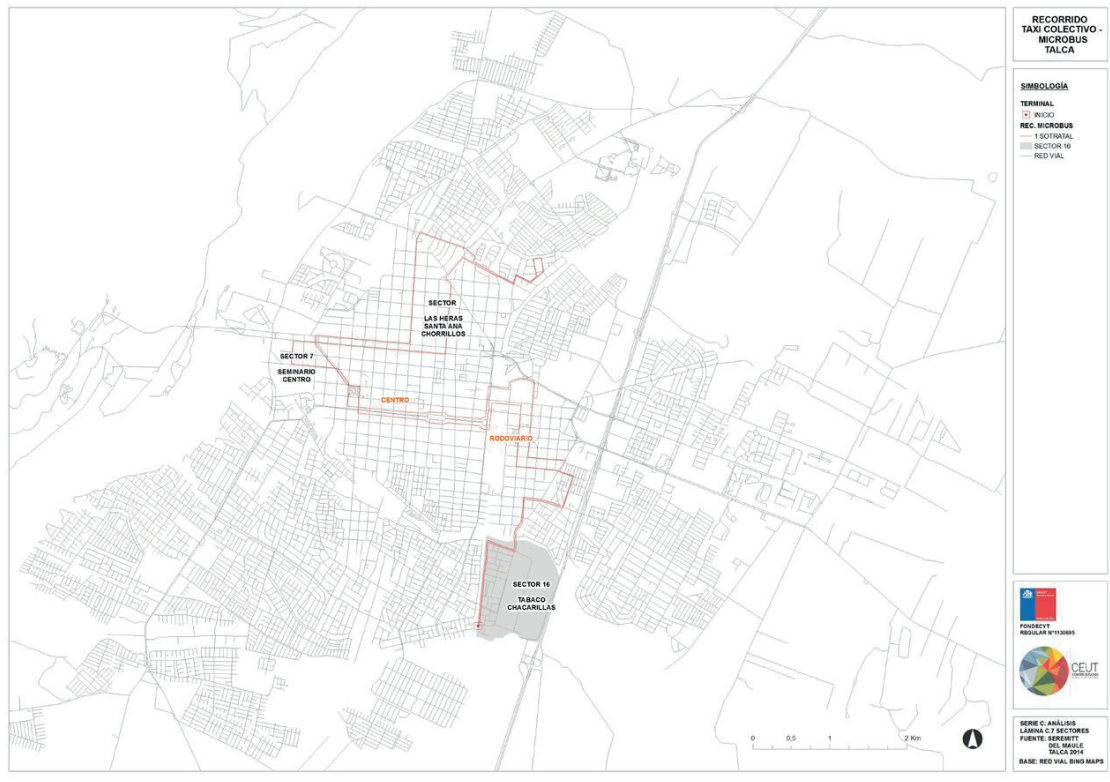

Fuente: Elaborado por Vania Reyes.

Figura $N^{\circ} 11$.

Mapa de oferta de locomoción sector Las Colines

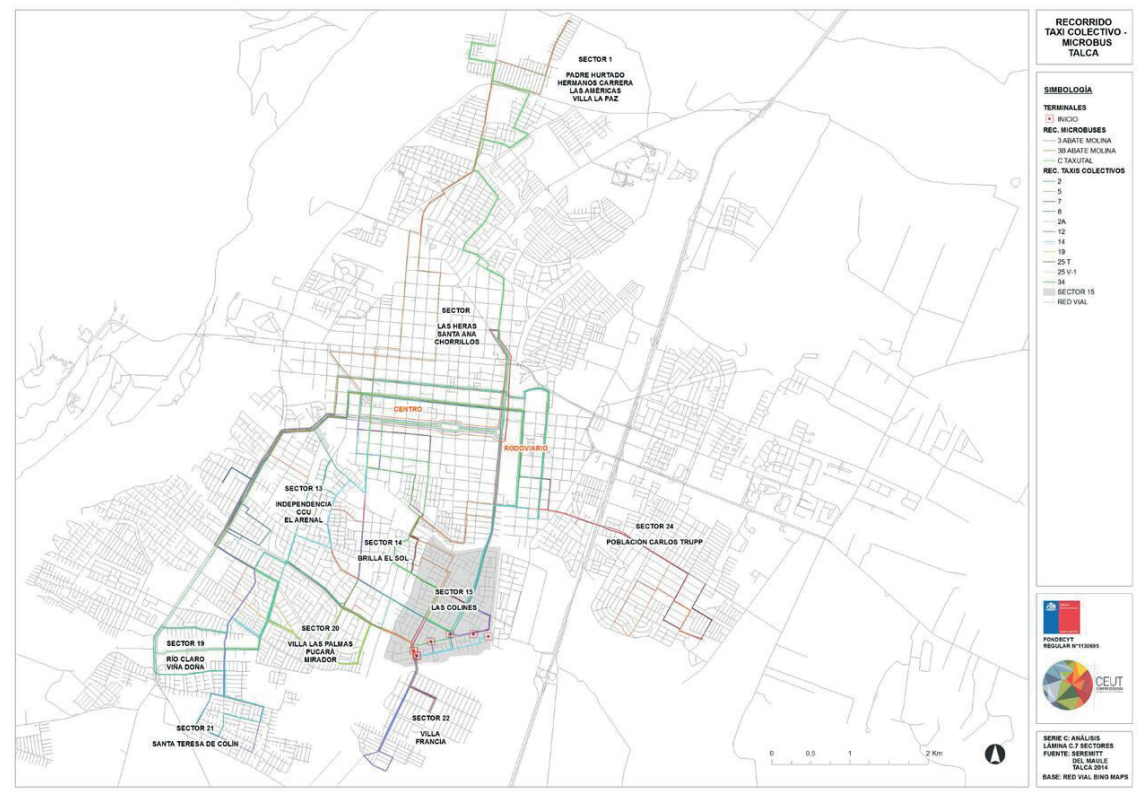

Fuente: Elaborado por Vania Reyes. 
Como puede apreciarse, el primer individuo solo puede dirigirse hacia el centro de la ciudad y parte del sector norte, mientras que el segundo individuo tiene una oferta mucho mayor, pudiendo acceder a diversos sectores de esta sin necesidad de transbordo. En ese sentido, este último posee un mayor potencial de movilidad. Se señalan estos casos ya que pese las diferencias, son barrios aledaños.

Los entrevistados por su parte, advierten que también existen dificultades relacionadas con la orientación de los recorridos del transporte público y con los barrios nuevos que se ubican en la periferia de la ciudad, donde existe solo uno o ningún recorrido. Los conjuntos habitacionales como Villa Francia, Villa Bicentenario y Don Pablo, son algunos ejemplos de ello:

“Tengo que hacer combinaciones, porque no hay nada de aquí que me lleve directo hacia el sur, por ejemplo, ahí estaría faltando, al sector sur. No hay conexión norte con el sur. Puede haber, norte con oriente, pero no el sector sur. Al poniente... sí... más o menos, llega la línea 1..." (Usuaria de transporte público, sector norte).

"Hasta ahora hay solamente de la línea 7 es la que llega allá y por cierto de allá trae a la gente al centro. La línea 7..." (Ciclista, sector oriente).

Ante las carencias del transporte público más eficaz, a saber, la micro (en términos de espacio y capacidad), la única opción es el taxi colectivo. Si bien, este transporte ha solventado en gran parte la falta de buses de la ciudad, también ha dejado en manos del gremio el tema de los precios y los recorridos. Cuando dicho gremio tiene la capacidad de manejar a voluntad los recorridos, cobrar tarifas diferidas según distancia y horario, quienes se encuentran en una posición menos ventajosa -en términos de movilidad- se ven en la obligación de pagar un transporte a un alto precio o bien, buscar otro medio más conveniente. Adicionalmente el taxi colectivo excluye a los estudiantes, quienes, al pagar la tarifa rebajada, no les queda más opción que depender de las micros para sus traslados $\mathrm{u}$ de otros medios alternativos como la caminata o la bicicleta. Si a esto le agregamos los factores viales ya expuestos, no ha de sorprendernos que en muchos hogares se decida acceder a un automóvil particular, cuando se dispone de los recursos necesarios.

Estos hechos provocan desigualdades en distintos planos: primero, una desigualdad en el acceso a la ciudad que poseen las personas según el sector donde habitan; segundo, una desigualdad en relación al costo que significa dicho acceso y tercero, desigualdades en relación a la experiencia de viaje que ofrece actualmente el sistema de transportes.

Como para la mayoría de quienes se desplazan regularmente la inmovilidad no es una opción, frente a escenarios adversos las personas van desarrollando formas particulares de superar los escollos del diario transitar, utilizando los recursos que se posean. Una de las prácticas más notables se refiere a la utilización del capital social.

"Sí, de hecho, no sé si será algo como normado, pero como que uno ya viene con eso integrado, si ves al vecino en la calle lo llevas, lo ayudas, no sé, o lo vas a dejar a la casa si vive más lejos que tú y ahí lo ayudas en todo sentido" (Usuario locomoción colectiva, sector oriente). 
Al parecer, las personas que residen en los lugares donde no existe locomoción colectiva, integran en sus prácticas de viaje cotidianas, la presencia de vecinos y amigos, desarrollando la costumbre de llevarse entre las familias del sector. Esta táctica merece atención ya que representa un tipo de solidaridad surgida de un problema común, y que va a contrapelo de la forma individual en la que la mayoría de las personas han intentado mejorar su potencial de movilidad.

Otro tipo de respuesta en función de mejorar las condiciones del viaje, es la combinación entre distintos modos de viaje. Este es el caso de quienes combinan el transporte público con la bicicleta: "Bueno, de repente como te digo dejo la bicicleta en la... a mitad de camino y la otra mitad lo doy en colectivo, como a veces el pique es bastante largo: son por lo menos uno 6-7 km". Menos común todavía, es que algunos, cansados de las colas en los tacos y el tránsito lento, hayan cambiado definitivamente su modo de viaje, accediendo a una bicicleta, aunque esta sea con motor:

“Sí, por ejemplo, yo opté por ella, porque, ya no sé po, antes yo andaba en bicicleta común, pero llegaba chata po, chata, o sea, lo único que quería era acostarme po. En cambio, acá no, porque yo salgo de mi trabajo, vengo, me desestreso por el camino, miro el paisaje, el viento en mi cara y es como rico po, y llego con ánimos de, de estar con mis niños".

Sea cual sea la modalidad, son habitualmente los menos beneficiados quienes se ven obligados a pensar mecanismos para trasladarse a sus destinos y cumplir las rutinas comprometidas, aunque en ocasiones la única opción sea caminar, levantarse al alba o gastar el doble en locomoción.

\section{Consideraciones finales}

El estudio de la movilidad, permitió rescatar la importancia que ha ido adquiriendo el viaje cotidiano en Talca, como consecuencia de las transformaciones en el ámbito urbano y del transporte. Cambios tales como el crecimiento expansivo, el aumento en el parque automotriz y las desigualdades en la oferta de transporte público han ido dificultando el acceso a la ciudad, provocando en las personas una mayor atención y preocupación por las distintas formas de movilización que se poseen. En ese sentido, es posible aseverar que mientras más complejas son las condiciones de movilidad o más dificultoso es acceder a los sitios en que los individuos se desempeñan, mayor preeminencia tendrá el viaje cotidiano a nivel de discurso, de su necesaria planificación y de los mecanismos para realizarlo satisfactoriamente. Lo anterior puede apreciarse en las diferencias observadas entre quienes viven dentro y fuera de la ciudad o entre quienes han desarrollado diversas maneras de mejorar sus condiciones de movilidad, ya sea mediante el acceso a un automóvil particular o bien, a través de su capital social.

Bajo esa idea, el conocimiento que manejan los actores que conducen, toman la locomoción colectiva, caminan o pedalean hacia sus destinos, constituye una vasta fuente que no solo informa acerca del estado del transporte en la ciudad, sino que además sobre las formas en que puede mejorarse. Algunas claves -surgidas durante las entrevistas- como la reorientación de ciertas calles para disminuir los tacos durante el horario punta, la reorganización del transporte público 
para surtir a los sectores con menor oferta y evitar pagar un pasaje diferido o un transbordo, fueron ideas que es importante recalcar y que debieran ser incluidas en instancias de planificación futuras. Por tanto, la necesaria actualización del plan de transportes de 2004, no debe basarse únicamente en estudios de carácter cuantitativo (EOD), como hasta ahora se ha realizado, sino que de igual forma debe incluir las percepciones y opiniones de los viajeros de la ciudad y de sus alrededores. La comprensión del viaje cotidiano y sus implicancias sociales, como elemento constitutivo de la planificación en transporte urbano, puede ser una futura línea de trabajo a desarrollar en ese sentido. Para ello, sin embargo, debe existir la voluntad de parte de las autoridades responsables para propiciar instancias más participativas de planificación, integrando en ella las actividades, conocimientos y usos históricos que los actores hacen de la ciudad durante sus viajes.

Por otra parte, mediante esta investigación fue posible dar cuenta de que las relaciones que se tejen en una ciudad como Talca no son homologables con las que suceden en la capital. Aunque el tiempo de viaje y el aislamiento no sean las principales problemáticas de este tipo de ciudades, sí existen otras complicaciones que el crecimiento urbano y automotriz han venido a impulsar: La generación de tacos y horarios punta, la pérdida de la costumbre de regresar al hogar para almorzar; y la disminución de viajes no motorizados, también nos permiten reconocer que dentro de este tipo de ciudades se gestan prácticas y dinámicas sociales diferentes de las que ocurren en la metrópoli. Debido a ello, es posible aseverar que en este tipo de ciudades aún no se consolida el modelo de desarrollo metropolitano, sino que más bien se encuentra en una etapa incipiente.

Es por esta razón que se hace necesario desarrollar un modelo de crecimiento que no sea un mero reflejo del implementado en Santiago, puesto que entendemos que estimula fuertemente la fragmentación, la segregación urbana y la contaminación ambiental. Las transformaciones ocurridas en Talca posterremoto, han seguido este esquema y han generado una disminución en la calidad de vida de muchos de sus habitantes, ya sea por el aumento en los tiempos de viaje, la inseguridad, el estrés o la contaminación ambiental. Son las ventajas que ofrece la "ciudad horario valle" (tranquilidad, seguridad, cercanía) las que comienzan a ser socavadas frente al fuerte avance de la modernización metropolitana, conceptualizadas en el imaginario de la "ciudad horario punta" que promueve la diferenciación y la desigualdad.

No obstante, aquí no se trata de hacer una defensa de lo tradicional frente a lo nuevo, sino de señalar el error que representa asumir que la metrópoli es sinónimo de modernización, en donde el crecimiento expansivo, el aumento de los flujos motorizados y la pavimentación exacerbada, parece ser la única manera de alcanzar el progreso. En cambio, la invitación es a reflexionar acerca de cómo es posible aspirar a una ciudad más equitativa, mejor planificada y más amable, a partir de las ventajas climáticas, morfológicas y culturales de la ciudad, promoviendo soluciones de movilidad que sean amigables con el medio ambiente y accesibles a toda la población. Propiciar una ciudad en la que se integren de forma armónica tanto la bicicleta como la caminata o donde el transporte público sea una verdadera alternativa frente al uso individual del automóvil, es promover una ciudad más justa e inclusiva, en especial para quienes, en este momento, poseen peores condiciones para acceder a ella y sus beneficios. 


\section{Referencias bibliográficas}

AMIN, A. Collective culture and urban public space. City: analysis of urban trends, culture, theory, policy, action, 2008, Vol. 12, No 1, p. 5-24.

AUGÉ, M. El viajero subterráneo. Un etnólogo en el metro. Barcelona: Gedisa, 2009.

AVELLANEDA, P. Movilidad, pobreza y exclusión social. Un estudio de caso sobre la ciudad de Lima. Barcelona: Tesis Doctoral, Departamento de Geografía, Universidad Autónoma de Barcelona, 2007.

CANALES, A. y CANALES, M. La Nueva Provincia: (Re)Poblamiento de los territorios agrarios. Chile 1982-2002. Revista Anales, 2012, №3, p. 157-173.

CANALES, A. y CANALES, M. De la metropolización a las agrópolis. El nuevo poblamiento urbano en el Chile actual. Polis, 2013, N 34. Disponible en Internet: http:// polis.revues.org/8729 ; DOI : 10.4000/polis.8729

CASTELLS, M. La era de la información. Economía Sociedad y Cultura. Buenos Aires: Siglo XXI Editores, 1999.

CASTORIADIS, C. La Institución Imaginada de la Sociedad. Madrid: Tusquets Editores, 1993.

CEBOLLADA, A. Aproximación a los proceso de exclusión social a partir de la relación entre el territorio y la movilidad. Documents d'Anàlisi Geogràfica, 2006, № 48, p. 105-121.

CEBOLLADA, À. y AVELLANEDA, P. Equidad social en movilidad: reflexiones en torno a los casos de Barcelona y Lima. Scripta Nova. Revista Electrónica de Geografía y Ciencias Sociales, 2008, Vol. XII, No 270 (47). Disponible en Internet: http://www.ub.edu/geocrit/sn/sn-270/sn-270-47.htm

Centro de Estudios Urbano Territoriales (CEUT). Encuesta de Caracterización Regional del Maule. Talca: Centro de Estudios Urbano Territoriales, Universidad Católica del Maule, 2014.

CRESSWELL, T. On the move. Mobility in the modern western world. New York/London: Routledge, 2006.

CRESSWELL, T. Towards a politics of mobility. Environment and Planning D: Society and Space, 2010, No 28, p. 17-33.

DE CERTEAU, M. La invención de la cotidiano 1. Artes de hacer. México: Universidad Iberoamericana, Departamento de Historia-Instituto Tecnológico y de Estudios de Occidente, 2000.

ELCl. Mapa de brechas territoriales de la ciudad de Talca. Talca: SUR Corporación de Estudios Sociales y Educación y ONG Surmaule, 2011. 
ERRÁZURIZ, T. ¿Donde estacionar? Prácticas cotidianas de reutilización, apropiación y resignificación del suelo santiaguino. En: TIRONI, M. y PÉREZ, F. (editores). SCL Espacios, Prácticas y cultura urbana. Santiago de Chile: ARQ Ediciones, 2009.

ERRÁZURIZ, T. Conductores, pasajeros y peatones: Fundamentos para una movilidad motorizada. Revista CA- Ciudad y Arquitectura, 2012, No 151. Disponible en Internet: http://revistaca.cl/revistas/151.pdf

ERRÁZURIZ, T. y VALDÉS, E. Tecnologías al acecho. Mutaciones del viaje en una ciudad no metropolitana. Universum, 2017, Vol. 32, N 1, p. 59 a 75

FALLOV, M.; JORGENSEN, A. \& KNUDSEN, L. Mobile Forms of Belonging. Mobilities, 2013, Vol. 8, $N^{\circ} 4$, p. $467-486$.

GARCÍA-CANCLINI, N.; CASTELLANOS, A. y ROSAS, A., La ciudad de los viajeros. Travesías e imaginarios urbanos: México, 1940-2000. México: Grijalbo, 1996.

HANAM, K.; SHELLER, M. \& URRY, J. Editorial: Mobilities, Immobilities and Moorings, Mobilities. Mobilities, 2006, Vol. 7, № 1, p. 1-22.

HIDALGO, R. La vivienda social en Santiago de Chile en la segunda mitad del siglo XX: Actores relevantes y tendencias espaciales. En: DE MATTOS, C.; DUCCI, M.E.; RODRÍGUEZ, A. y YÁÑEZ WARNER, G. (editores). Santiago en la Globalización: ¿Una nueva ciudad? Santiago de Chile: Instituto de Estudios Urbanos y Territoriales, Pontifica Universidad Católica de Chile y Ediciones SUR, 2004. p. 219-242.

HIERNAUX, D. Los imaginarios urbanos: de la teoría y los aterrizajes en los estudios urbanos. Eure, 2007, Vol. XXXIII, N 99, p. 17-30.

INSTITUTO NACIONAL DE ESTADÍSTICA (INE). Encuesta nacional de caracterización socioeconómica. Santiago de Chile: INE, 2006.

INSTITUTO NACIONAL DE ESTADÍSTICA (INE). Encuesta nacional de caracterización socioeconómica. Santiago de Chile: INE, 2013.

INSTITUTO NACIONAL DE ESTADÍsTICA (INE). Parque de Vehículos en circulación 2013. Santiago de Chile: INE, 2014.

INSTITUTO NACIONAL DE ESTADÍSTICA (INE). Compendio Estadístico 2013. Santiago de Chile: INE, 2014.

JIRÓN, P. Unravelling invisible inequalities in the city through urban daily mobility. The case of Santiago de Chile. Swiss Journal of Sociology, 2007, №33, p. 45-68.

JIRÓN, P. Mobile Borders in Urban Daily Mobility Practices in Santiago de Chile. International Political Sociology, 2010, N4, p. 66-79. 
JIRÓN, P. Las consecuencias del urbanismo fragmentador en la vida cotidiana de habitantes de la ciudad de Santiago de Chile. Eure, 2014, Vol. 40, Nº 121, p. 5-28.

JOUFEE, Y. y LAZO, A. Las prácticas cotidianas frente a los dispositivos de la movilidad. Aproximación política a la movilidad cotidiana de las poblaciones pobres periurbanas de Santiago de Chile. Eure, 2010, Vol. 36, № 108, p. 29-47.

KAUFMANN, V. \& FLAMM, M. Operationalising the Concept of Motility: A Qualitative Study. Mobilities, 2006, $N^{\circ} 2$, p. 167-189.

LAZO, A. Transporte, movilidad y exclusión. El Caso del Transantiago en Chile. Scripta nova. Revista Electrónica de Geografía y Ciencias Sociales, 2008, Vol. 12, № 270. Disponible en Internet: http://www.ub.edu/geocrit/sn/sn-270/sn-270-45.htm

LETELIER, F. y BOYCO, P. Talca posterremoto: una ciudad en disputa. Modelo de reconstrucción, mercado inmobiliario y ciudadanía. Santiago de Chile: Ediciones SUR, 2011.

LINDÓN, A. Los imaginarios urbanos y el constructivismo geográfico: los hologramas espaciales. Eure, EURE, 2007, Vol. XXXIII, N 99, p. 31-46.

MATTIOLI, G. Moving through the city with strangers? Public transport as a significant kind of urban public space. In: SHORTELL, T. \& BROWN, E. (editors). Walking in the European City: Quotidian Mobility and Urban Ethnography. Ashgate: 2013, p. 57-74.

MENDIZABAL, E. ¿Hay alguna geografía humana que no sea geográfica histórica? Revista de Geografía Norte Grande, 2013, N 54, p. 31-49

MINVU Y GEOCIUDAD CONSULTORES LTDA. Análisis de Tendencias de Localizción. Caso: Ciudad de Talca. Talca: Informe Final, 2007.

MIRALLES-GUASCH, C. Ciudad y transporte. El binomio imperfecto. Barcelona: Ariel Geografía, 2002.

MINISTERIO DE TRANSPORTE Y TELECOMUNICACIONES. Recorridos locomoción colectiva. Talca: MTT, 2014.

MUÑOZ, D. Imaginarios en movimiento. Análisis de tramas de sentido en el transporte público de Santiago de Chile. Santiago de Chile: Tesis de Magíster, Instituto de Estudios Urbanos y Territoriales, Pontificia Universidad Católica de Chile, 2013.

RIVEROS, S. Recopilación de antecedentes cuantitativos y espaciales que den cuenta de los cambios socio territoriales generados por la agroindustria en la relación urbano - rural en la Región del Maule. Santiago de Chile: Informe de práctica Profesional en CEUT, Escuela de Geografía, Facultad de Arquitectura y Urbanismo, Universidad de Chile, 2013.

SALERNO, B. Un viaje por la movilidad cotidiana. El espacio entre el transporte y el individuo. Perspectiva Geográfica, 2012, Vol. 17, p. 213-232. 
SCHIEFELBUSCH, M. Handling the mobile subjects' subjectivity: Rationality and emotion in transport planning and research. In: HOLZ-RAU, C. \& SCHEINER, J. (editors). Subject-oriented approaches to transport. Dortmund: IRPUD, 2009.

SHELLER, M. \& URRY, J. The New Mobilities paradigm. Enviroment and Planning, 2006, № 36, p. 207-226.

PEARCE, L. Automobility in Manchester Fiction. Mobilities, 2012, Vol. 7, No 1, p. 93-113.

SPINNEY, J. A place of sense: a kinaesthetic ethnography of cyclists on Mont Ventoux. Environment and Planning: Society and Space, 2006, N²4, p. 709-732.

URETA, S. To Move or Not to Move? Social Exclusion, Accessibility and Daily Mobility among the Low-income Population in Santiago, Chile. Mobilities, 2008, Vol. 3, № 2, p. 269-289.

URETA, S. Manejando por Santiago: explorando el uso de automóviles por parte de habitantes de bajos ingresos desde una óptica de movilidad sustentable. EURE, 2009, Vol. 35, Nº 105, p. 71-93. 